\title{
Comparison of Telecommunication Markets in Europe Using Multivariate Statistical Analysis
}

\author{
Pawel Kossecki \\ Polish National Film, Television and Theater School \\ Łódź, Poland
}

kossecki@poczta.onet.pl

\begin{abstract}
Common problem in valuation of telecommunication companies is finding comparable data and markets for valuation. The aim of this work was to identify comparable markets for the telecommunication market in Europe. A method for comparison of the markets based on the Multivariate Statistical Analysis was presented. The study covers twenty-two European countries. Using taxonomic measures, these countries were divided into five groups, taking into account the following variables: average monthly service cost of the fixed Internet, average cost of the mobile usage, and average cost of the fixed telephony usage. Within individual groups, the costs of telecommunications services are less diverse than in the entire population; their members can be considered comparable markets. The same method can be used for comparing markets in cases of enterprise valuations in the telecommunication sector, and also in analysis of their level of development.
\end{abstract}

Keywords: Telecommunication, valuation, taxonomy, taxonomic measures, $K$-Means, Multivariate Statistical Analysis

\section{Introduction}

The telecommunication market has undergone tremendous changes, mainly due to the introduction of new technologies. Some new challenges like introduction of $5 \mathrm{G}$ network already appeared. Telecoms stock valuation has worse performance than general indexes [7]. The sector was closely examined by private equity investors and consolidation process. Many operators developed mainly due to the acquisitions. Currently telecom operators work in a high competitive as well as still fragmented market. One of the latest example is takeover of Multimedia by Vectra in Poland (respectively second and third largest cable operator). Combining network will cover 4.4 million households, and the subscriber base will reach 1,7 million, creating the largest operator in the country [24]. Once just providing traditional analogue voice transmission, now attract their customers with high-speed Internet access, mobile telephony, TV retransmission, energy and other services, delivered at very competitive prices. Demand for connectivity over both mobile and fixed broadband networks is on the rise across Europe. Comparing consumer prices for communication services against a general basket, the prices for telecoms have consistently decreased in the last decade [7]. Telecom operators should be considered as companies using the 
so-called subscription-based business model, where the customer pays a fixed subscription fee for access to a product or service. The level of monthly ARPU (average revenues per user) from basic telecommunication service is rather low in most of the EU countries. Moreover, there is a large dispersion between Western and Central-Eastern Europe; specific for the Central-Eastern European countries is the quite low nominal ARPU.

Current models for creating value are strongly related to concept of CLV (Customer Lifetime Value) mainly due to the high customer acquisition costs [18], [19]. It creates the necessity for very careful evaluations of the profitability of the clients during their whole lifetime. The most popular indicators, which characterize the economic situation of the enterprise in the telecommunication sector, usually taken into consideration during the valuation, are ARPU and EBITDA margin (EBITDA earnings before interest, taxes, depreciation and amortization). Telecommunication companies must very well understand the structure of their client's revenues and costs, to maximize revenues and margins from all services. Telecoms are typical CAPEX (capital expenditures) driven companies, so the level of prices for service is most important factor influencing profitability and level of valuation [19], [20].

Following types of basic services are being sold:

- access to the Internet,

- mobile service,

- telecommunication service.

In addition, telecommunication companies sell a whole range of supplementary services like TV service or sale of content. Revenues from typical telecommunication services decreased in the last decade. It was partly compensated by sale of other services. ARPU is under strong pressure. Strong, parallel competition in the broadband Internet sector and mobile service results in high pressure to cut prices [19].

In the case of operators working in small markets, a common problem is finding comparable data for valuation.

Author presented a model for comparison of the markets based on Multivariate Statistical Analysis. This method can be used for comparing markets in cases of enterprise valuations in the telecommunication sector.

Results of the telecommunication market analysis may be very useful in the case of valuation of small telecommunication companies operating in the Central-Eastern Europe. In some countries, there is a lack of data related to comparable companies and international comparisons must be made.

With organic growth opportunities narrowing, telecom players need a better way to screen potential M\&A targets [3].

When conducting a valuation based on multiples, the biggest challenge is picking the right economic parameters as the multiples, which help to identify key value drivers of the enterprise and choose proper markets to compare [19].

EV/EBITDA is the most common ratio in the telecommunication sector and most widely used multiple based on enterprise value (EV). EBITDA is largely unaffected by accounting differences and is neutral to the capital structure of the company. Quite commonly in the sector is used also EV/number of subscribers. In both cases problem 
is to find comparable companies and comparable markets. When comparing companies operating in various markets, it is necessary to note differences in business/economy cycles, which particularly strongly influence the growth rate and future revenues.

\section{Methodology Overview}

The difficulties with using market comparison for financial valuations are due to the problem of collecting accurate data in different countries and finding comparable markets. In the analysis shown below, market comparison methodology supported by taxonomic measures was applied.

It is usually possible to find markets with higher and lower levels of EBITDA as well as margin and the most important problem is to compare markets with objective criteria.

The objective of the investigations presented in what follows is the recognition and classification of similarities and differences between European countries, related to the telecommunication market. For this purpose, the formalism and methods of multivariate comparative statistical analysis will be used. These methods are necessary tools to be applied in quantitative analysis of objects represented by many variables [6].

The result of the quantitative comparative analysis is, in general, the appropriate grouping of the objects considered, that is partition into groups of similar objects, significantly different from objects assigned to other groups. The notion of similarity is connected with the notion of distance between objects. The number of groups and their characteristics are not given in advance. The objective is rather to reveal and classify the existing similarities and dissimilarities [6].

The $K$-means clustering procedure described below groups the data points into $K$ clusters and defines the center positions of each cluster [5], [16], [21]. It's one of the simplest unsupervised learning algorithms that solve the well-known clustering problem [16].

\subsection{Organization of Data and Clustering}

In the frames of the multivariate statistical analysis, the set of data represents, in general, measurements of many variables related to the set of objects considered. Assume that measurement refers to $m$ variables; $m \geq 2$. It is to be represented by the vector-function:

$$
\boldsymbol{X}=\left[X_{1}, X_{2}, \ldots, X_{m}\right]
$$

Consider now measurements on the set of $n$ objects. Measurement on the object $i$ is to be represented by the point vector $\mathbf{x}_{\mathrm{i}}$ :

$$
\mathbf{x}_{i}=\left\{x_{i 1}, x_{i 2}, \ldots, x_{i m}\right\}, \quad(i=1,2, \ldots, n)
$$

Measurements on the set of $n$ objects are to be represented by the $n \times m$ matrix:

$$
\mathbf{X}=\left[x_{i j}\right]
$$


where $x_{i j}$ is the measurement of the $j$-th variable on the $i$-th object.

Measurements of different variables are expressed, in general, in different units. Most methods of the multivariate comparative analysis may be applied if measurements are given in the same units and are of comparable order Many different types of clustering methods have been proposed in the literature [1], [10], [11], [14]. Despite such a diversity, some methods are more frequently used [25]. Also, many of the commonly employed methods are defined in terms of similar assumptions about the data [23]. Several different approaches to clustering have been proposed in the literature [4], [12], [23].

Different normalization procedures can be applied. The most common is standardization of the variables [13]:

$$
\begin{aligned}
& z_{j}=\left\{z_{1 j}, z_{2 j}, \ldots, z_{n j}\right\},(j=1,2, \ldots, m) \\
& z_{i j}=\left(\frac{x_{i j}-\bar{x}_{j}}{s_{j}}\right), \quad(i=1,2, \ldots, n ; j=1,2, \ldots, m)
\end{aligned}
$$

where:

$z_{i j}$ - standardized value of the variable $X_{j}$ on the $i$-th object,

$\bar{x}_{j}$ - arithmetic average of the variable $X_{j}$,

$s_{j}-$ standard deviation of the variable $X_{j}$.

The mean value of the standardized variable is zero and its standard deviation is 1. Standardized data allows us to easily distinguish objects which are below or above average with relation to specific variables.

To compare items described by many variables, the notion of similarity - and dissimilarity - is necessary and must be formally defined. In the multivariate comparative analysis, the measure of dissimilarity is the distance between objects, represented as points in the space of standardized variables. It is called statistical distance [15]. Most commonly used is the Euclidean distance between objects:

$$
d_{i l}=\sqrt{\sum_{j=1}^{m}\left(z_{i j}-z_{l j}\right)^{2}},(i, l=1,2, \ldots, n)
$$

where:

$d_{i l}$ - distance between objects $i$ and $l$,

$z_{i j}$ - normalized value of the variable $X_{j}$ on the $i$-th object.

\subsection{K-means method}

The main idea of the $K$-Means method is to define $K$ centroids, one for each cluster. Partition into $K$ clusters $C_{k}$ is to be realized by minimization of the function $G$, which represents overall scattering of points within clusters:

$$
\begin{aligned}
& \left\{C_{k}\right\},(k=1,2, \ldots, K) \rightarrow \min G \\
& G=\sum_{k=1}^{K} \sum_{i \in C_{k}} \sum_{j=1}^{m}\left(z_{i j}-\gamma_{k j}\right)^{2}
\end{aligned}
$$


where $\gamma_{\mathbf{k}}$ is the point vector representing mean position of objects assigned to the cluster $C_{k}$; it is called center of gravity of the cluster:

$$
\gamma_{k j}=\frac{1}{n_{k}} \sum_{i \epsilon C_{k}} z_{i j}
$$

The function $G$ may be thus represented in the form:

$$
G=\sum_{k=1}^{K} \sum_{i \in C_{k}}\left(g_{i k}\right)^{2}
$$

where $g_{i k}$ is the Euclidean distance between the object $i$, which belongs to the cluster $C_{k}$, and the center of gravity of this cluster.

The appropriate choice of $K$ is problem and domain dependent and generally a user tries several values of $K$ [2], [15].

The final number of clusters may be specified in advance or determined as part of the clustering procedure. In this paper, the second approach will be used.

Finding a partition into clusters that corresponds to the minimum of the overall scattering function is a mathematical task - to be solved numerically - that usually has a specific solution. This solution is distinguished by the fact that any reassignment of items significantly increases the overall scattering of points within clusters.

\section{Partition of European Countries into Groups in View of Their Telecommunication Markets}

Aggregated data related to the telecommunication market and main statistics for a group of twenty-two selected European countries are presented in Table 1. The group includes countries for which comparable data were available, collected using well defined methodology [8]. The following basic variables describing the market were considered:

- $\quad$ INT - average monthly service cost for the medium speed Internet 30 $\mathrm{GB} />=10 \mathrm{Mb} / \mathrm{s}$ for speeds from $30,7 \mathrm{Mb} / \mathrm{s}$ to $102,4 \mathrm{Mbit} / \mathrm{s}$ (EUR, including VAT);

- $\quad \mathrm{MOB}$ - average monthly cost of using mobile services with low usage of services (EUR, including VAT);

- FIX - monthly cost of basket for a moderately active user of fixed lines telecommunication services (EUR, including VAT).

These data describe the level of prices of the relevant services, which may be considered as important from the point of view of the average moderately active user, and indirectly the level of profitability. All prices are given in EUR.

Correlation coefficients between those variables, and additionally correlations with GDP p.c., are presented in Table 2. Correlations between all the variables considered are not high; only of some importance are correlations between the Internet cost and the fixed line cost, and also between the fixed line cost and GDP p.c. Correlations between GDP p.c. and the mobile and Internet cost are definitely weak; GDP p.c. will not be taken into account in the partition procedure.

Partition of twenty-two countries into five clusters, based on the standardized values of the variables INT, MOB and FIX has been examined. Results of the partition 
represented in standardized variables are presented in Table 3. Last column in Table 3 shows standardized distances between objects (countries) and the cluster centroids.

The clusters are as follows:

- Cluster 1: Hungary, Finland, Latvia, Slovakia and Czech Republic,

- Cluster 2: Poland, Estonia and Slovenia,

- Cluster 3: Sweden, Germany, Austria, Denmark, Italy, Belgium, Portugal, France, Netherlands, Luxembourg and United Kingdom,

- Cluster 4: Ireland and Spain,

- Cluster 5: Greece.

\begin{tabular}{|c|l|c|c|c|c|}
\hline $\begin{array}{c}\text { \# of } \\
\text { case }\end{array}$ & Country & $\begin{array}{c}\text { GDP p.c. } \\
\text { (EUR) }\end{array}$ & $\begin{array}{c}\text { INT } \\
\text { (EUR) }\end{array}$ & $\begin{array}{c}\text { MOB } \\
\text { (EUR) }\end{array}$ & $\begin{array}{c}\text { FIX } \\
\text { (EUR) }\end{array}$ \\
\hline 1 & Austria & 37810 & 28,60 & 10,00 & 60,46 \\
2 & Belgium & 35600 & 31,90 & 7,70 & 43,89 \\
3 & Czech Republic & 17620 & 25,90 & 11,60 & 12,80 \\
4 & Denmark & 48260 & 29,00 & 8,30 & 31,11 \\
5 & Estonia & 15090 & 29,30 & 5,10 & 18,44 \\
6 & Finland & 36820 & 17,50 & 4,30 & 29,04 \\
7 & France & 32830 & 34,10 & 5,10 & 39,61 \\
8 & Germany & 35860 & 27,40 & 9,50 & 34,18 \\
9 & Greece & 17780 & 50,00 & 9,10 & 37,21 \\
10 & Hungary & 57960 & 44,30 & 21,70 & 51,77 \\
11 & Ireland & 26760 & 31,50 & 13,40 & 43,11 \\
12 & Italy & 12180 & 18,70 & 7,80 & 16,40 \\
13 & Latvia & 83470 & 38,50 & 9,70 & 42,98 \\
14 & Luxembourg & 41540 & 35,70 & 6,40 & 43,69 \\
15 & Netherlands & 12430 & 27,00 & 3,90 & 14,08 \\
16 & Poland & 18110 & 33,20 & 7,60 & 50,91 \\
17 & Portugal & 15560 & 18,70 & 6,30 & 23,02 \\
18 & Slovakia & 20170 & 36,80 & 4,20 & 20,57 \\
19 & Slovenia & 24880 & 47,70 & 18,80 & 49,76 \\
20 & Spain & 43810 & 26,40 & 9,20 & 33,68 \\
21 & Sweden & 32700 & 40,50 & 5,60 & 49,63 \\
22 & United Kingdom & $\mathbf{3 0 9 0 0}$ & $\mathbf{3 1 , 2 4}$ & $\mathbf{8 , 8 6}$ & $\mathbf{3 4 , 7 9}$ \\
\hline & Average & $\mathbf{1 7 0 6 6}$ & $\mathbf{9 , 2 3}$ & $\mathbf{4 , 3 6}$ & $\mathbf{1 3 , 7 1}$ \\
\hline & St. deviation & & & & \\
\hline
\end{tabular}

Table 1. Basic Parameters Related to the Telecommunication Market in twenty-two European Countries [8], [22]. 


\begin{tabular}{|c|c|}
\hline Variables & $\begin{array}{c}\text { Correlation } \\
\text { Coefficient }\end{array}$ \\
\hline INT:MOB & 0,413 \\
\hline INT:FIX & 0,585 \\
\hline MOB:FIX & 0,424 \\
\hline GDP:INT & 0,308 \\
\hline GDP:MOB & 0,287 \\
\hline GDP:FIX & 0,517 \\
\hline
\end{tabular}

Table 2. Correlation Coefficients.

Standardized distances between cluster centroids are listed in Table 4. Standardized distances between members of particular clusters and cluster centroids are in all cases smaller than distances between centroids, which vary from 1,535 for Cluster 1 and Cluster 2 to 4,639 for Cluster 1 and Cluster 4.

Partition to clusters in original variables is represented in Table 5. Clusters and countries within clusters are ordered according to the rising of the Internet cost.

Figures 1 and 2 depict two-dimensional projections of the cluster distributions onto the planes (FIX, INT) and (INT, MOB).

\begin{tabular}{|c|c|c|c|c|c|}
\hline Cluster & Country & INT & МOB & FIX & $\begin{array}{l}\text { Stand. } \\
\text { distance }\end{array}$ \\
\hline \multirow{5}{*}{ C1 } & Hungary & $-1,802$ & 0,170 & $-1,156$ & 0,625 \\
\hline & Finland & $-1,488$ & $-1,046$ & $-0,419$ & 1,072 \\
\hline & Latvia & $-1,358$ & $-0,243$ & $-1,341$ & 0,270 \\
\hline & Slovakia & $-1,358$ & $-0,587$ & $-0,858$ & 0,433 \\
\hline & Czech Republic & $-0,578$ & 0,629 & $-1,603$ & 1,240 \\
\hline \multicolumn{2}{|r|}{ Centroid 1} & $-1,317$ & $-0,215$ & $-1,075$ & \\
\hline \multirow{3}{*}{$\mathrm{C2}$} & Poland & $-0,459$ & $-1,138$ & $-1,510$ & 0,523 \\
\hline & Estonia & $-0,210$ & $-0,862$ & $-1,192$ & 0,253 \\
\hline & Slovenia & 0,602 & $-1,069$ & $-1,037$ & 0,660 \\
\hline \multicolumn{2}{|r|}{ Centroid 2} & $-0,022$ & $-1,023$ & $-1,246$ & \\
\hline \multirow{10}{*}{ C3 } & Sweden & $-0,524$ & 0,078 & $-0,081$ & 0,961 \\
\hline & Germany & $-0,416$ & 0,147 & $-0,044$ & 0,881 \\
\hline & Austria & $-0,286$ & 0,262 & 1,872 & 1,387 \\
\hline & Denmark & $-0,243$ & $-0,128$ & $-0,268$ & 0,945 \\
\hline & Italy & 0,028 & 1,042 & 0,607 & 1,150 \\
\hline & Belgium & 0,071 & $-0,266$ & 0,664 & 0,184 \\
\hline & Portugal & 0,212 & $-0,289$ & 1,176 & 0,610 \\
\hline & France & 0,310 & $-0,862$ & 0,352 & 0,819 \\
\hline & Netherlands & 0,483 & $-0,564$ & 0,649 & 0,583 \\
\hline & Luxembourg & 0,786 & 0,193 & 0,598 & 0,720 \\
\hline
\end{tabular}




\begin{tabular}{|c|c|c|c|c|c|}
\hline Cluster & Country & INT & МОВ & FIX & $\begin{array}{l}\text { Stand. } \\
\text { distance }\end{array}$ \\
\hline & United Kingdom & 1,003 & $-0,748$ & 1,083 & 1,187 \\
\hline \multicolumn{2}{|r|}{ Centroid 3} & 0,129 & $-0,103$ & 0,601 & \\
\hline \multirow[b]{2}{*}{$\mathrm{C} 4$} & Ireland & 1,414 & 2,946 & 1,239 & 0,387 \\
\hline & Spain & 1,782 & 2,281 & 1,092 & 0,387 \\
\hline \multicolumn{2}{|r|}{ Centroid 4} & 1,598 & 2,614 & 1,165 & \\
\hline C5 & Greece & 2,032 & 0,055 & 0,177 & 0,000 \\
\hline \multicolumn{2}{|r|}{ Centroid 5} & 2,032 & 0,055 & 0,177 & \\
\hline
\end{tabular}

Table 3. Partition of twenty-two European Countries into Five Clusters Using $K$-means Method; Standardized Variables.

\begin{tabular}{|l|l|l|l|l|l|}
\hline Cluster & C1 & C2 & C3 & C4 & C5 \\
\hline C1 & 0,000 & 1,535 & 2,217 & 4,639 & 3,585 \\
C2 & 1,535 & 0,000 & 2,069 & 4,655 & 2,722 \\
C3 & 2,217 & 2,069 & 0,000 & 3,140 & 1,955 \\
C4 & 4,639 & 4,655 & 3,140 & 0,000 & 2,777 \\
C5 & 3,585 & 2,722 & 1,955 & 2,777 & 0,000 \\
\hline
\end{tabular}

Table 4. Standardized Distances between Cluster Centroids.

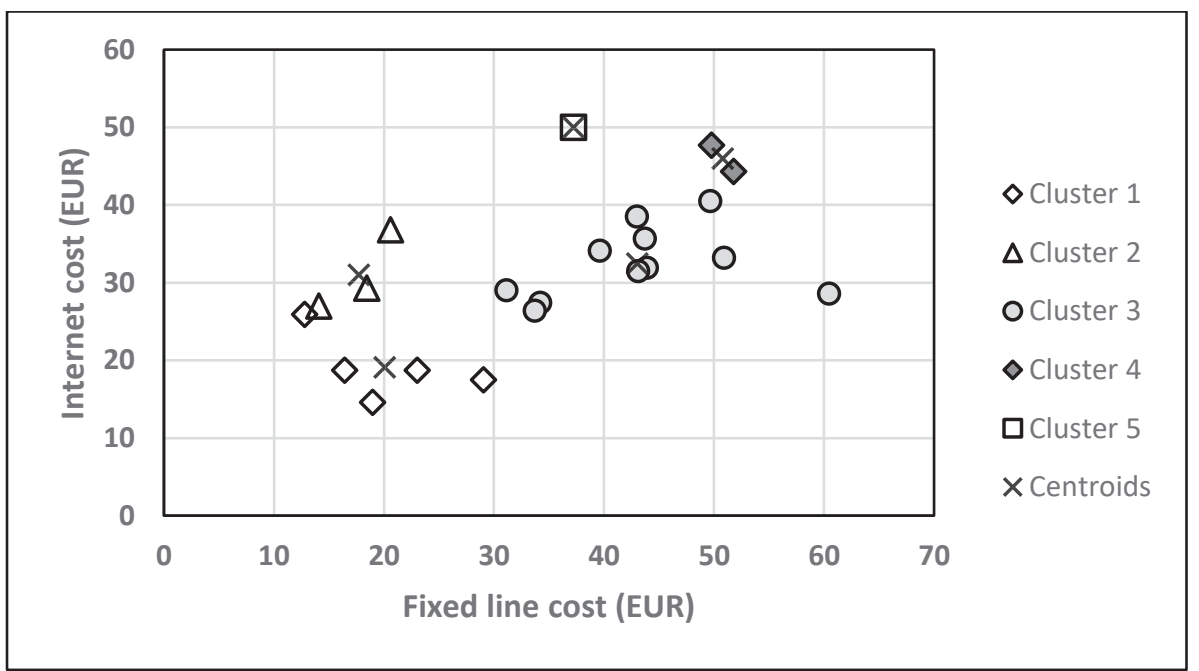

Figure 1. Average monthly Internet cost vs. fixed line cost in distinguished clusters of twenty-two European countries. 


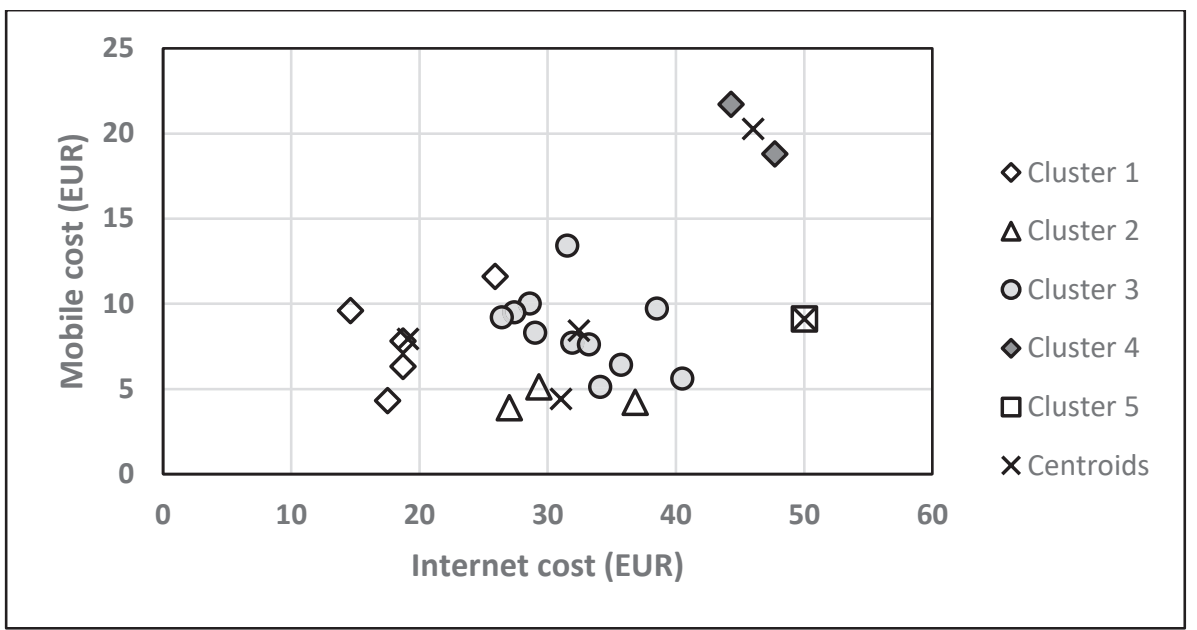

Figure 2. Average monthly mobile cost vs. Internet cost in distinguished clusters of twenty-two European countries

\begin{tabular}{|c|c|c|c|c|c|}
\hline Cluster & Country & $\begin{array}{c}\text { GDP p.c. } \\
\text { (EUR) }\end{array}$ & $\begin{array}{c}\text { INT } \\
\text { (EUR) }\end{array}$ & $\begin{array}{l}\text { MOB } \\
\text { (EUR) }\end{array}$ & $\begin{array}{c}\text { FIX } \\
\text { (EUR) }\end{array}$ \\
\hline \multirow{5}{*}{$\mathrm{C} 1$} & Hungary & 12560 & 14,60 & 9,60 & 18,94 \\
\hline & Finland & 36820 & 17,50 & 4,30 & 29,04 \\
\hline & Latvia & 12180 & 18,70 & 7,80 & 16,40 \\
\hline & Slovakia & 15560 & 18,70 & 6,30 & 23,02 \\
\hline & Czech Republic & 17620 & 25,90 & 11,60 & 12,80 \\
\hline \multicolumn{2}{|r|}{ Centroid 1} & 18948 & 19,08 & 7,92 & 20,04 \\
\hline \multirow{3}{*}{$\mathrm{C} 2$} & Poland & 12430 & 27,00 & 3,90 & 14,08 \\
\hline & Estonia & 15090 & 29,30 & 5,10 & 18,44 \\
\hline & Slovenia & 20170 & 36,80 & 4,20 & 20,57 \\
\hline \multicolumn{2}{|r|}{ Centroid 2} & 15897 & 31,03 & 4,40 & 17,70 \\
\hline \multirow{11}{*}{$\mathrm{C} 3$} & Sweden & 43810 & 26,40 & 9,20 & 33,68 \\
\hline & Germany & 35860 & 27,40 & 9,50 & 34,18 \\
\hline & Austria & 37810 & 28,60 & 10,00 & 60,46 \\
\hline & Denmark & 48260 & 29,00 & 8,30 & 31,11 \\
\hline & Italy & 26760 & 31,50 & 13,40 & 43,11 \\
\hline & Belgium & 35600 & 31,90 & 7,70 & 43,89 \\
\hline & Portugal & 18110 & 33,20 & 7,60 & 50,91 \\
\hline & France & 32830 & 34,10 & 5,10 & 39,61 \\
\hline & Netherlands & 41540 & 35,70 & 6,40 & 43,69 \\
\hline & Luxembourg & 83470 & 38,50 & 9,70 & 42,98 \\
\hline & United Kingdom & 32700 & 40,50 & 5,60 & 49,63 \\
\hline
\end{tabular}




\begin{tabular}{|c|c|c|c|c|c|}
\hline Cluster & Country & $\begin{array}{c}\text { GDP p.c. } \\
\text { (EUR) }\end{array}$ & $\begin{array}{c}\text { INT } \\
\text { (EUR) }\end{array}$ & $\begin{array}{l}\text { MOB } \\
\text { (EUR) }\end{array}$ & $\begin{array}{c}\text { FIX } \\
\text { (EUR) }\end{array}$ \\
\hline \multicolumn{2}{|r|}{ Centroid 3} & 39705 & 32,44 & 8,41 & 43,02 \\
\hline \multirow[b]{2}{*}{ C4 } & Ireland & 57960 & 44,30 & 21,70 & 51,77 \\
\hline & Spain & 24880 & 47,70 & 18,80 & 49,76 \\
\hline \multicolumn{2}{|r|}{ Centroid 4} & 41420 & 46,00 & 20,25 & 50,77 \\
\hline $\mathrm{C5}$ & Greece & 17780 & 50,00 & 9,10 & 37,21 \\
\hline \multicolumn{2}{|r|}{ Centroid 5} & 17780 & 50,00 & 9,10 & 37,21 \\
\hline \multicolumn{2}{|r|}{ Average } & 30900 & 31,24 & 8,86 & 34,79 \\
\hline
\end{tabular}

Table 5. Basic Parameters Related to the Telecommunication Market in Five Clusters of European Countries.

Cluster 1 constitutes four Central-Eastern European countries: Hungary, Latvia, Slovakia and Czech Republic together with Finland. Those countries are characterized by the comparatively low cost of the telecommunication services; average values for the cluster of the average monthly service cost for the medium speed Internet, average monthly cost of using mobile services and also monthly cost of basket for a moderately active user of the fixed lines telecommunication services are mostly below the averages for the whole group of twenty-two countries. The only exceptions are the cost of mobile service in Hungary and the Czech Republic, above the average for all countries, compensated in the Czech Republic by the low cost of the fixed lines services. GDP p.c. for the first four countries from this cluster is much below the average; only Finland is here an exception, with its GDP p.c. above the average for the whole group.

Cluster 2 includes three countries: Poland, Estonia and Slovenia, characterized by the very low cost of the mobile service and the fixed lines services, but much higher than in Cluster 2 cost of the medium speed Internet, close to the average for the whole group of twenty-two countries. GDP p.c. in this group (cluster) of countries is below the average for the whole group.

Cluster 3 is the largest; it includes eleven Western European countries: Sweden, Germany, Austria, Denmark, Italy, Belgium, Portugal, France, Netherlands, Luxembourg and United Kingdom, with GDP p.c. mostly above average, except for Portugal and Italy. The cost of Internet in this group is not very diverse; the lowest is in Sweden and the highest in the United Kingdom. The cost of mobile connections is more diversified; the lowest is in France and the highest in Italy. Also the cost of the fixed lines services is diversified; the lowest is in Denmark and the highest in Austria.

Cluster 4 includes two countries: Ireland and Spain, characterized by the high cost, much above the average, of all the services.

Cluster 5 constitutes Greece itself, with its highest cost of the Internet and at the same time mobile and fixed line service cost only slightly above the average. 
Figure 3 depicts average monthly costs of the basic telecommunication services as compared with the average GDP p.c. in subsequent clusters.

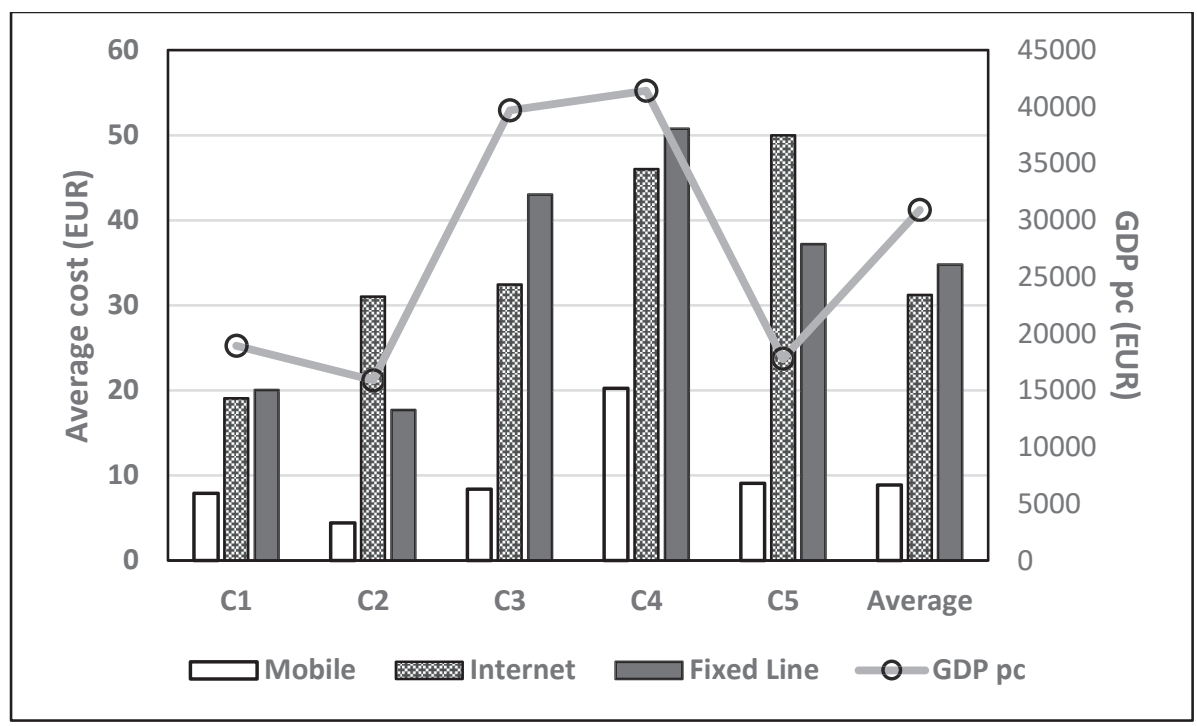

Figure 3. Average monthly cost of telecommunication service as compared with the average GDP p.c. in clusters of European countries distinguished using taxonomic analysis (see Table 2)

\section{Conclusions}

In the group of twenty-two European countries, several subgroups (clusters) can be distinguished, whose members can be considered as comparable markets to the telecommunication market.

Central-Eastern European countries, together with Finland, belong to two subgroups:

- C1: Hungary, Latvia, Slovakia, Czech Republic and Finland,

- C2: Poland, Estonia and Slovenia.

The first one is characterized by the comparatively low cost of all the telecommunication services, whereas the second one is characterized by the low cost of the mobile and fixed line service, however the medium speed Internet cost as in the West Europe countries.

Western European countries constitute 3 subgroups:

- C3: Sweden, Germany, Austria, Denmark, Italy, Belgium, Portugal, France, Netherlands, Luxembourg and United Kingdom,

- C4: Ireland and Spain,

- C5: Greece.

The most numerous group C3, with the PP adjusted GDP p.c. mostly above the average for the whole group of twenty-two countries, is characterized by the medium speed Internet cost not very different from the average for this group, and at the same time by rather diversified cost of the mobile connections and the fixed lines services. 
Group C4, Ireland and Spain, is characterized by the high cost, much above the average, of all the services, and group C5, Greece itself, is characterized by the very high cost of the medium speed Internet.

In general, prices of the medium speed Internet and the mobile service are not related to the level of the PP adjusted GDP p.c.; in some relatively rich countries the level of those prices is comparable to that in the Central-Eastern European countries, with comparatively low GDP p.c. Only the fixed line services costs are clearly higher in reach Western European countries.

The method to identify comparable markets described here has been used also for classification of telecommunication markets for valuation purposes. In some countries, there is a lack of data related to comparable companies and international comparison must be applied. The method is useful mainly because the comparison is based on public data and outcome is related to economic profits. It can help telecom companies to choose proper markets to find acquisition targets.

In business decision support environment, each cluster represents European countries with comparable market conditions. For those countries similar pricing policy can be applied. It is especially important for multinational companies with centralized management. Detailed analysis of different clusters is also extremely important when comparing markets in a different stage of development. It allows managers to predict market situation in mid- and long-term perspective on less developed markets.

The analysis should be extended by more variables and clustering of the companies from different continents (especially North America). Extension of the analysis by EBITDA ratio (commonly used for the valuation cable operators) and average service penetration, will allow for more detailed study concerning competitive situation in different countries and its impact on valuation of cable operators.

\section{References}

[1] C. C. Aggarwal, C. K. Reddy, "Data Clustering: Algorithms and Applications", vol. 2. 1st ed. Chapman \& Hall/CRC, 2013

[2] K. Alsabti, S. Ranka, V. Singh, “An efficient k-means clustering algorithm", Syracuse University, Electrical Engineering and Computer Science, 43, https://surface.syr.edu/eecs/43, 1997

[3] O. Bosch, S. Nagel, J. Tiefel, "A better way to M\&A: Zeroing in on telecom value", https://www.mckinsey.com/industries/telecommunications/our-insights/abetter-way-to-m-and-a-zeroing-in-on-telecom-value, November 2016, Telecommunication Insights, Mc Kinsey \& Company

[4] F. Camastra, A. Verri, "A novel kernel method for clustering", IEEE Transactions on Pattern Analysis and Machine Intelligence. 2005, 27(5):801-805. pmid: 15875800 
[5] M. E. Celebi, H. A. Kingravi, P. A. Vela, "A Comparative Study of Efficient Initialization Methods for the K-Means Clustering Algorithm", Expert Systems with Applications, 40(1), January 2013, 200-210, https://doi.org/10.1016/j.eswa.2012.07.021

[6] J. Dziechciarz, "Econometrics. Methods, examples, exercises", Wrocław University of Economics Publishing House, Wrocław, 2003

[7] European Telecommunications Network Operators' Association, “Annual Economic Report 2017”, https://etno.eu/datas/publications/economicreports/ETNO\%20Annual\%20Economic\%20Report\%202017\%20(final\%2 0version\%20web).pdf

[8] Eurostat, GDP per capita at market prices, https://ec.europa.eu/eurostat/web/products-datasets/-/sdg_08_10, 2019

[9] J. Garcia, J. Fdez-Valdivia, F. Cortijo, R. Molina, "Dynamic Approach for Clustering Data”, Signal Processing, 44(2), 1994

[10] S. Guha, R. Rastogi, K. Shim, "Cure: an efficient clustering algorithm for large databases", Information Systems, 26(1):35-58, https://doi.org/10.1016/S0306-4379(01)00008-4, 2001

[11] J. Huang, H. Sun, J. Kang, J. Qi, H. Deng, Q. Song, "ESC: An efficient synchronization-based clustering algorithm”, Knowledge-Based Systems, 40:111-122, 2013

[12] L. Jing, M. K. Ng, J. Z. Huang, “An entropy weighting k-means algorithm for subspace clustering of high-dimensional sparse data", IEEE Transactions on knowledge and data engineering, 19(8):1026-1041, 2007

[13] R. A. Johnson, D. W. Wichern, “Applied Multivariate Statistical Analysis”. 6th ed., Prentice-Hall, Englewood Cliffs, NJ, 2007

[14] G. Karypis, E. H. Han, V. Kumar, “Chameleon: Hierarchical clustering using dynamic modeling”, Computer, 32(8):68-75, 1999

[15] L. Kaufman, P. J. Rousseeuw, "Finding Groups in Data: an Introduction to Cluster Analysis", John Wiley \& Sons, 1990

[16] T. M. Kodinariya, P. R. Makwana, "Review on determining number of Cluster in K-Means Clustering", International Journal of Advance Research in Computer Science and Management Studies, 1(6), 2013

[17] P. Kossecki, „Kreowanie i pomiar wartości przedsiębiorstwa w świecie Internetu", PWSFTViT Publishing House, Łódź, 2011

[18] P. Kossecki, „Powiązanie zarządzania wartością przedsiębiorstwa i zarządzania sprzedażą wśród operatorów kablowych", Problemy Zarządzania, 1/2012 (35):164-178, 2012 
[19] P. Kossecki, "Valuation and Value Creation of Cable TV Operators: Cable Retransmission and Copyright Fees", PWSFTViT Publishing House, Łódź, 2015

[20] P. Kossecki, K. Kompa, "Valuation of cable operators - decision tree and synthetic measure of development method (SMR) for market comparison", 80th International Atlantic Economic Conference, 9-11.10.2015, Boston

[21] A. Likas, N. Vlassis, J. J. Verbeek, "The global k-means clustering algorithm”, Pattern Recognition, 36 (2):451-461, Feb. 2003

[22] Office of Electronic Communications, "Report on the state of the telecommunications market in Poland in 2018"

[23] M. Z. Rodriguez, C. H. Comin, D. Casanova, O. M. Bruno, D. R. Amancio, L. da F. Costa, F. A. Rodrigues "Clustering algorithms: A comparative approach" PLOS ONE 14(1), 2019: e0210236, https://doi.org/10.1371/journal.pone.0210236

[24] Telecomparer, "Vectra completes takeover of Multimedia Polska", https:/www.telecompaper.com/news/vectra-completes-takeover-ofmultimedia-polska--1324994, 03.02.2020

[25] X. Wu, V. Kumar, J. R. Quinlan, J. Ghosh, Q. Yang, H. Motoda, G. J. McLachlan, A. Ng, B. Liu, P. S. Yu, Zhi-Hua Zhou, M. Steinbach, D. J. Hand, D. Steinberg, "Top 10 algorithms in data mining", Knowledge and information Systems, 14(1):1-37, https://doi.org/10.1007/s10115-0070114-2, 2008 